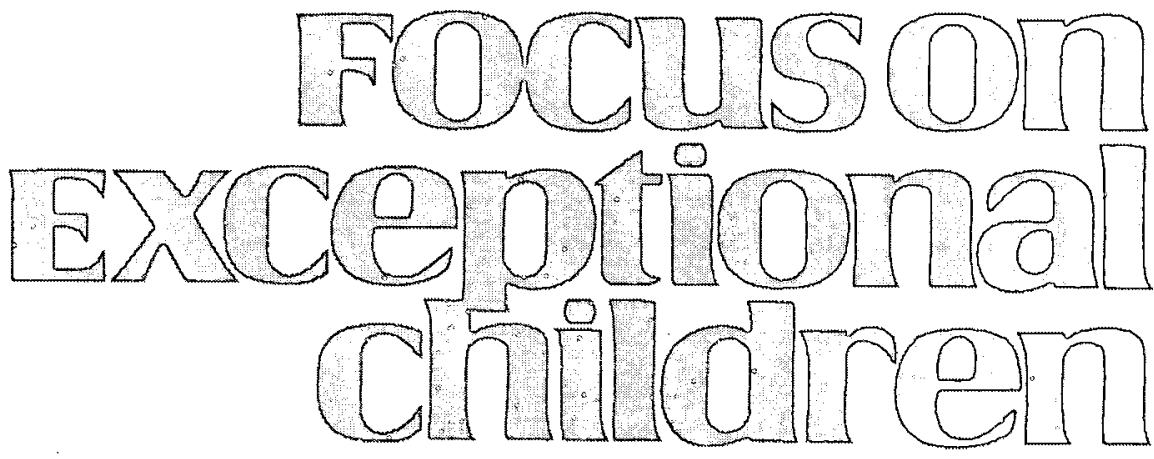

\title{
Literacy, Assistive Technology, and Students with Significant Disabilities
}

\author{
Karen A. Erickson, Penelope Hatch, and Sally Clendon
}

Literacy is a national educational priority. During the last decade, unprecedented funds have been committed to ensuring that school children, particularly those at risk for literacy-learning difficulties, have access to research-based instruction that is most likely to support their development as readers and writers. Yet, for the thousands of students across the country with significant intellectual disabilities, literacy instruction is a distant goal, and information regarding research-based instruction is extremely limited. Adding to the challenge is the absence of information regarding the use of assistive technology to support access to the curriculum and learning for students with significant intellectual disabilities. In this article, we review the research and apply understandings and strategies used in literacy instruction for students without disabilities to students with significant intellectual disabilities.

\section{Students with Significant Intellectual Disabilities}

This article specifically addresses students with significant disabilities including intellectual disabilities. In the United States, approximately $1 \%$ of school-aged students have intellectual disabilities (U.S. Department of Education, 2002). These are "characterized by significant limitations both in intellectual functioning and adaptive behavior as expressed in conceptual, social, and practical adaptive skills" and that originate before the age of 18 (American Association of Intellectual and Developmental Disabilities [AAIDD], 2009, para. 2). The term mental retardation has been used historically to describe this set of disabilities; however, the current preferred term is intellectual disability (AAIDD, 2009). The term intellectual disabilities has several synonyms, including cognitive disability (Centers for Disease Control, 2005), intellectual impairment (State of Queensland Department of Education, 2006), cognitive impairment (Beukelman \& Mirenda, 2005), and developmental disability (U.S. Department of Health and Human Services, 2008). In this article, we use the term intellectual disabilities to represent all of these.

Dr. Erickson is the Director of the Center for Literacy \& Disability Studies and a professor at the University of North Carolina at Chapel Hill. Dr. Hatch is a research associate at the Center for Literacy \& Disability Studies at the University of North Carolina at Chapel Hill. Dr. Clendon is a senior lecturer in the Speech Language Therapy Programme at Massey University, Auckland, New Zealand. 
Varying degrees of intellectual disability influence learning and the acquisition of adaptive skills differentially. The ways in which various degrees of intellectual disability are defined have changed over time. The Diagnostic and Statistical Manual of Mental Disorders (DSM-IV-TR; American Psychiatric Association, 2000) relies on IQ scores to determine the severity of an individual's intellectual disabilities. Specifically, these levels are:

mild or educable, as indicated by an IQ level of 50-55 to approximately 70 ;

moderate or trainable, as indicated by an IQ level of $35-40$ to $50-55$;

severe, as indicated by an IQ level of 20-25 to 35-40; and

profound, as indicated by an IQ level below 20 or 25 .

A more recent classification of the degree of intellectual disability focused on the level of support an individual requires rather than the person's IQ level (Luckasson, Borthwick-Duffy, \& Buntix, 2002). The range of support includes

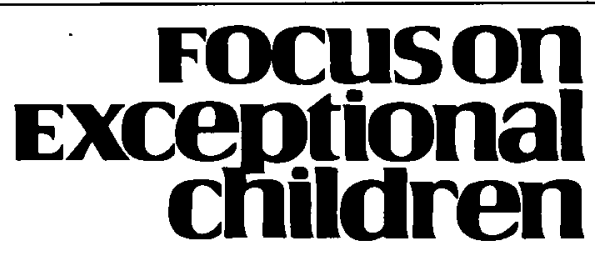

ISSN 0015-511X FOCUS ON EXCEPTIONAL CHILDREN (USPS 203-360) is published monthly except June, July, and August as a service to teachers, special educators, curriculum specialists, administrators, and those concerned with the special education of exceptional children. This publication is annotated and indexed by the ERIC Clearinghouse on Handicapped and Gifted Children for publication in the monthly Current Index to Journals in Education (CIJE) and the quarterly index, Exceptional Children Education Resources (ECER). The full text of Focus on Exceptional Children is also available in the electronic versions of the Education Index. It is also available in microfilm from Serials Acquisitions, National Archive Publishing Company, P.O. Box 998, Ann Arbor, MI 48106-0998. Subscription rates: individual, \$48 per year; institutions, $\$ 66$ per year. Copyright $\odot 2010$, Love Publishing Company. All rights reserved. Reproduction in whole or part without written permission is prohibited. Printed in the United States of America. Periodical postage is paid at Denver, Colorado. POSTMASTER: Send address changes to:

Love Publishing Company

Executive and Editorial Office P.O. Box 22353

Denver, Colorado 80222

Telephone (303) 221-7333

\section{CONSULTING EDITORS}

Steve Graham Vanderbilt University
Ron Nelson

University of Nebraska-Lincoln
Eva Horn

University of Kansas intermittent, limited, extensive, and pervasive. The current article focuses specifically on the $15 \%-20 \%$ of students diagnosed with intellectual disabilities who require extensive or pervasive levels of support or fall into the moderate to severe and profound categories, and it is grounded in the belief that all students can make progress as readers and writers regardless of their level of intellectual functioning.

\section{Literacy}

Literacy is used narrowly in this article to refer specifically to reading and writing (i.e., the cognitive processes of comprehending and composing meaning in written texts). This narrow definition is used in lieu of broader definitions that define idiosyncratic, nonconventional, and often symbol-based behaviors of students with significant intellectual disabilities as literate behaviors (Downing, 2005). Certainly, these behaviors are valuable as students develop their abilities to communicate meaningfully with others and participate in print-based activities, but these idiosyncratic, nonconventional, and symbol-based behaviors are emergent literacy behaviors at best. The danger in describing them as literate behaviors is that students with significant intellectual disabilities might be denied meaningful, intensive, ongoing opportunities to further develop their reading and writing skills and understandings because the skills and behaviors they are already demonstrating will be viewed as sufficient. As Koppenhaver (2000) stated:

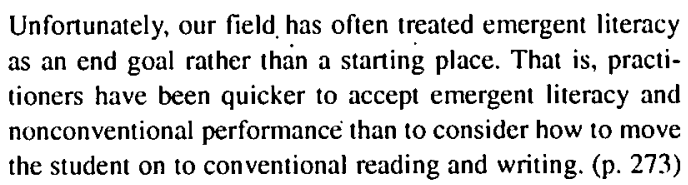

\section{Reading and Writing Focus}

The narrow focus on literacy as reading and writing is not intended to exclude students, as Downing (2005) warned. Rather, it is intended to ensure that the focus remains on research-based practices that build knowledge, skills, and abilities with the potential to result in reading and writing skills. Current laws mandate that all students be provided with access to the general curriculum. It is no longer acceptable to offer educational programs to students with significant intellectual disabilities that focus solely on developing other life or functional skills. In this article, we also take the position that it should be unacceptable to provide access to content without developing knowledge, skills, and understandings that will promote lifelong learning.

In the general education setting, literacy is an integral part of the curriculum. Beyond the obvious reading and writing demands in the areas of English and language arts, other core curriculum areas, such as science, social studies, 
and math, also present numerous literacy challenges. Without the ability to read and write, students can learn skills and information across the curriculum but cannot learn important lifelong skills that allow them to independently revisit and build on that information in the future.

\section{Emergent Literacy}

Literacy is narrowly defined as reading and writing in this article, but information is also provided to help students move toward this conventional use of reading and writing by supporting their emergent literacy learning. Emergent literacy is best defined as the reading and writing behaviors that precede and develop into conventional reading and writing (Teale \& Sulzby, 1986). The vast majority of students with significant intellectual disabilities are currently emerging in their understandings and use of print. They are working to understand the functions of print and print conventions, phonological awareness, alphabet knowledge, and important receptive and expressive language skills such as vocabulary, syntax, and narrative skills.

\section{Assistive Technology and \\ Literacy Learning}

Assistive technology (AT), as defined by the Individuals with Disabilities Education Act (2004), consists of "any item, piece of equipment, or product system, whether acquired commercially off the shelf, modified, or customized, that is used to increase, maintain, or improve functional capabilities of individuals with disabilities." The law also defines AT services as "any service that directly assists a child with a disability in the selection, acquisition, or use of an assistive technology device." Appropriate and ongoing provision of AT services combined with carefully selected AT devices can minimize the numerous challenges faced by students with significant intellectual disabilities as they attempt to hold books, see standard print, use a pencil or standard keyboard, and employ numerous other skills required for reading and writing.

Despite its use for more than two decades, AT as a support for students with disabilities is not well understood (Matvy, 2000), and minimal empirical evidence is available to support AT in educational settings (Edyburn, 2003). The existing research has produced mixed results and has led to declarations of the "urgent need" to produce relevant and useful research about AT (Edyburn, 2005, p. 60). Students with significant intellectual dișabilities, however, cannot wait for research on AT to support their engagement in meaningful literacy learning and use. Without immediate access to AT, most students with significant intellectual disabilities will fail to access information and successfully engage as learners.
Through their work on Universal Design for Learning, Rose and Meyer (2002) were the first to make the distinction between AT to support access to information and AT to support access to learning. The purpose of the distinction was to help educators understand that maximizing access sometimes undermines learning. For example, if the educational goal for a student is to learn to decode words, providing the student with access to screen-reading software and digitized text will make it more difficult, not easier, for the student to reach the goal.

Many students with significant intellectual disabilities have co-occurring sensory or physical disabilities or both, which adds meaning to the distinction between access to information and access to learning. Assistive technology can be used to circumvent the challenges imposed by sensory and physical disabilities; however, as stated by Boone and Higgins (2007), "Mere access to the content is inadequate as an AT unless that access is mediated by instructional design supports appropriate for the specific disability of the user" (p. 138). Nowhere is this more important than in the educa- tion of students with significant intellectual disabilities who require intensive instructional supports.

\section{Picture-Supported Text: An Example}

The use of picture-supported text is one AT approach that is used widely with students who have significant intellectual disabilities. It provides a specific example of an approach with the potential to provide access to content while impeding access to learning reading skills. Picturesupported text involves pairing or replacing text with picture symbols (Downing, 2005). Software programs such as Boardmaker v.6 (Mayer-Johnson, 2006), PixWriter v.3 (Slater Software, 2008), and Writing with Symbols 2000 v.2.6 (Widgit Software, 2002) allow the user to type in or import running text and automatically or easily produce a picture symbol paired with each word. Although this practice is intended to provide access to text that a student could not read otherwise, it potentially makes it more difficult for the student to develop reading and writing skills (Pufpaff, Blischak, \& Lloyd, 2000; Rose \& Furr, 1984; Saunder \& Solman, 1984).

For multiple reasons, pairing picture symbols with words may limit access to learning to read. Pictures actually may increase confusion, especially when they represent abstract concepts, have multiple meanings, or serve more than one grammatical function (Hatch, 2009). This is particularly true when words do not have obvious picture referents, as is the case with verbs such as $d o$ and $i s$. Because they do not have picture referents, they must be represented by abstract, arbitrary symbols (see Figure 1). While the orthographic (print) representation of these words is also abstract, printed words appear much more frequently and are understood more 
do

is

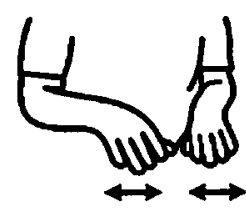

Source: From Boardmaker (Version 6) software (Pittsburgh: MayerJohnson, 2006).

\section{FIGURE 1 \\ Boardmaker Picture Communication Symbols for the Verbs Do and Is}

broadly than are abstract picture symbols. As a result, students learning to read the words rather than recognize the abstract picture symbols have more opportunities to encounter the words and interact with others who understand them.

Picture symbols may also make learning to read more challenging when they represent multi-meaning words such as back and play. Each of these words has a consistent spelling across its multiple meanings, and neither spelling conjures a visual image that is related more closely to one meaning than another. In contrast, picture symbols representing these words offer visual representations of a single meaning. Consider the word back, which has a single spelling for its noun, verb, and adjective interpretations. The reader must use the words that surround it to know for certain which form is being used. In contrast, picture symbols might represent just the noun form of this word by illustrating a person's back, the back of a room, book, or building, or the athlete who is in the back position on the field.

These are just a few of the options for representing only the noun form of this word, and each choice communicates a clear meaning that may or may not match the intended use in a given context. Although today's software offers the option to select specific symbols for each use, words such as back and play would require students to learn literally dozens of symbolic representations with varying abstractness.

Beyond the potential confusion introduced when pictures are paired with words, pairing pictures with words seems to make it more difficult for students to learn to read the words. More than four decades ago, researchers began investigating the impact of pictures on the development of word identification for readers with and without disabilities of all ages. In the earliest of these studies (Samuels, 1967), first graders were more successful during training when pictures were paired with words, but the advantage of pictures disappeared when the students were asked to read the words without the pictures. With pictures, these students seemed to be learning more successfully during instruction, but in the end, they found it easier to read the words they learned without the benefit of pictures. In a follow-up study, other first graders receiving reading instruction that included pictures paired with words learned more slowly than did their peers who did not have pictures.

In a subsequent study (Singer, Samuels, \& Spiroff, 1973-1974), more than 160 first- and second-grade students were randomly assigned to one of four intervention groups: picture + word; no picture + word; picture + sentence; and no picture + sentence. All of the students engaged in trials until they could identify the words without pictures present. The students had more correct responses during the training and learned words in fewer trials in the word-only conditions (no picture + word, no picture + sentence) than they did in the conditions that included pictures. These findings were replicated later for kindergarten nonreaders without disabilities (Blischak \& McDaniel, 1995).

Research involving children and adults with intellectual disabilities has supported the findings of these studies involving typical primary-grade students. For example, Singh and Solman (1990) investigated the impact of pictures paired with words on the word reading skills of eight students with intellectual disabilities. All of the students read the fewest number of words correctly when they learned those words when paired with pictures. Similarly, the adults with intellectual disabilities studied by Pufpaff et al. (2000) learned to read printed words more easily than they learned to read words paired with pictures or words printed in enhanced ways with the picture embedded in the printed word.

A study by Fossett and Mirenda (2006) provided some guidance on how pictures should be used in reading instruction for students with intellectual disabilities. The authors used pictures to teach two students with intellectual disabilities to read individual words. In one method, the students were taught to read the words when they were paired directly with the pictures, and the second method required students to match the pictures to the printed words. The students were more successful when they actively matched pictures to printed words than they were when the words were paired with the picture.

\section{Implications}

Given the evidence suggesting that pairing pictures with words makes it more difficult to learn to read the words, educators must be clear regarding their goal when they choose to use technology to produce picture-supported text. If the goal is merely to provide access to content and careful 
attention is paid to selecting picture symbols that reflect the meaning of the words in the text, it is reasonable to expect that pictures will increase access to content that otherwise would not be accessible. If the goal is to improve reading skills, however, pairing pictures with text is likely to slow the rate at which students develop those skills. The research provides clear evidence that pictures should not be paired with words that students are expected to learn to read or spell. In either case, AT decisions require that we consider both access to content and access to learning if we want to ensure that students achieve their goals.

\section{Emergent Literacy}

Emergent literacy is composed of nonconventional—often idiosyncratic - behaviors and understandings that beginning readers and writers exhibit prior to achieving conventional literacy (see, e.g., Teale \& Sulzby, 1986). Emergent literacy is a function of experience rather than development and, therefore, is not linked to a specific age level or level of cognitive or linguistic skill. Young children necessarily are emerging in literacy understandings because they have not had the experience required to be conventional readers and writers. Also, the literacy understandings of older children, adolescents, and adults might be emerging because they have not had adequate literacy learning experience.

Emergent literacy, reading, and writing exist along a continuum. Students with emerging understandings of literacy can be taught conventional literacy skills in isolation. The research literature is full of studies demonstrating that individuals with significant intellectual disabilities who have emerging understandings of literacy can learn to identify sight words in isolation (see Browder \& Xin, 1998) long before they have developed basic concepts about print, alphabet knowledge, oral language understandings, or phonological awareness.

The problem with this approach is that development of these other basic concepts, skills, and understandings is required for word-identification skills to be used meaningfully in reading with comprehension (Dickinson, McCabe, Anastasopoulos, Peisner-Feinberg, \& Poe, 2003; Nation \& Snowling, 2004; Storch \& Whitehurst, 2002). When sight words are taught in isolation without careful attention to development of these other concepts, skills, and understandings, emerging readers and writers struggle to use their word-reading skills to support their attempts to read, write, or communicate with others.

Successful progress as an emergent reader and writer requires that students be active and involved learners who apply their own "primitive hypotheses" (Clay, 2005, p. 9) when given opportunities to explore and interact with print (Sénéchal, LeFevre, Smith-Chant, \& Colton, 2001). Emergent literacy understandings cannot be developed by completing tasks independently or learning skills in isolation. Instead, students must be actively involved in constructing their understandings of print, language, and the connections between the two by interacting with more literate others across multiple contexts and for multiple purposes.

\section{The National Early Literacy Panel (NELP)}

In the spring of 2009, the National Institute for Literacy (NIFL) published the Report of the National Early Literacy Panel. The National Early Literacy Panel (NELP) conducted a synthesis of the research regarding emerging literacy skills in children from birth through age 5. The NELP reports on five areas of intervention: code-focused interventions, shared reading, parent and home programs, preschool and kindergarten programs, and language enhancement. The NELP concluded that interventions across the five areas had a moderate to large effect on emergent literacy learning and that each influenced later conventional reading and writing development for the young children without disabilities who were included in the research they reviewed.

Although the NELP did not include research regarding students with disabilities in its review, the NELP findings can guide decisions regarding appropriate emergent literacy interventions for students with significant intellectual disabilities. For example, the NELP found that code-related interventions focusing on building phonological awareness and alphabetic knowledge (letter names and sounds) have a direct, positive impact upon the later development of conventional reading and writing skills. Similarly, shared book experiences that promote interactions and engagement have a direct, positive impact on later conventional literacy skills.

In contrast, the NELP provides no evidence to suggest that we should teach students who are emerging in their understandings of reading and writing to identify sight words. Although it is commonly recommended that functional sight word reading be integrated into the day-to-day instructional program of students with significant intellectual disabilities who are emerging in their literacy understandings (see e.g., Browder \& Spooner, 2006), these sightword identification skills have no relationship with later conventional word reading skills (Ehri, 2005). Thus, the time and energy spent teaching functional sight words do not contribute to future conventional reading and writing abilities and could be better spent on language and other skills that will contribute to later success.

Research addressing the areas identified by the NELP involving students with significant intellectual disabilities is limited; however, the research that does exist provides important information regarding the nature of the emergent literacy intervention that we should provide. Three studies addressing emergent literacy development for students with 
significant intellectual disabilities are described here. Two of the studies reported on classroom interventions and the third reported on a parent intervention. In all cases, the interventions reflect at least some of the findings of the NELP (NIFL, 2009).

\section{MEville to WEville Programs}

MEville to WEville: Early Literacy and Communication Curriculum (AbleNet, 2004). The first classroom study (Erickson, Clendon, Abraham, Roy, Van de Carr, 2005) investigated the impact of this curriculum on the early literacy development of 23 children with significant intellectual disabilities. The teachers were supported to use AT to assist the children as they engaged in emergent literacy activities such as book sharing, code-focused interventions, and other lessons to support vocabulary and language learning. After 8 weeks of intervention, the children demonstrated moderate gains in print knowledge (Cohen's $d=.51$ ).

MEville to WEville (AbleNet, 2004). This program is an early literacy and communication program designed specifically to address the needs of students with significant intellectual disabilities. It does so by offering teachers an integrated set of lessons that provide students with the opportunity to be active and involved learners who apply their own "primitive hypotheses" (Clay, 2005, p. 9) when given opportunities to explore and interact with print (Senechal, LeFerve, Smith-Chant, \& Colton, 2001). It is important that MEville to WEville supports teachers in integrating AT throughout instruction to provide access to information while supporting learning.

This program reflects the findings of the NELP (NIFL, 2009) by including shared reading, code-related interventions, parent and home connections, and language learning lessons. It is the only commercially available program that addresses each of these areas while supporting teachers in integrating appropriate AT into each lesson. Whether teachers use the actual program or look to it as a model to organize their own emergent literacy intervention program, the MEville to WEville (AbleNet, 2004) program provides an important approach to building the emergent literacy understandings that are most likely to promote later conventional reading and writing success.

\section{Other Classroom Interventions}

In another classroom intervention, Koppenhaver and Erickson (2003) evaluated the impact of emergent literacy interventions for preschool-aged children with a diagnosis of autism and significant intellectual disabilities. The interventions involved dramatically increasing access to reading, writing, and print-related activities while also increasing the level of interactions with adults in the classroom during the activities. Assistive technology was used in a number of ways to support the children in their efforts to interact with books (e.g., adapted traditional books, books on the computer), engage in writing (e.g., letter stamps, alternate keyboards, standard computers with talking word processors), and develop their alphabet knowledge and phonemic awareness (e.g., voice output communication devices, computer software).

As children used this wide range of AT, they interacted with researchers and classroom staff. They received no explicit instruction in literacy skills, but the adults were intentional in their efforts to develop the children's emergent literacy understandings while interacting with print. In 4 months, the children had gained understanding in concepts of print, alphabet knowledge, and writing skills, suggesting that the approach was successful in helping these children with significant intellectual disabilities.

As described by Koppenhaver and Erickson (2003), the intervention involved several features that reflect the finding of the NELP (NIFL, 2009). For example, students were provided with AT to support them in commenting, labeling, and otherwise interacting actively while engaged in shared reading with adults. Students were provided with access to letters and sounds through various toys, games, and AT that allowed them to explore and receive feedback regarding letters, sounds, and phonological awareness.

\section{Parent and Home Programs}

At least one study demionstrates that parent programs can be as effective for students with significant disabilities as they are for the typically developing children in the research reviewed by the NELP (NIFL, 2009). Skotko, Koppenhaver, and Erickson (2004) taught mothers of girls with Rett syndrome to use simple AT, including augmentative communication strategies to improve the quality of book-sharing interactions with their daughters. For example, the mothers were taught to relate events in the book to their child's experience and ask more prediction and inference questions, even though their children had limited means of communication and could not respond precisely.

Mothers also were taught to respond to their child's attempts by attributing meaning and to encourage efforts to use the simple augmentative communication devices by prompting the communication act rather than the physical act of hitting the switch. Finally, the mothers were taught to dramatically increase the wait time they provided so their children could respond more successfully to their questions or initiate comments of their own. The intervention led to improved communication for the girls. The parent booksharing intervention in this study led to some of the same types of gains that resulted in the large effect size for parentdirected book-sharing interventions analyzed by the NELP (NIFL, 2009). 


\section{Summary}

These studies provide a convergence of evidence suggesting that students with significant intellectual disabilities who are emerging in their understandings of print benefit from many of the same types of interventions that yield strong effects on language and literacy outcomes for children without disabilities. Importantly, these interventions focus both on the areas of intervention identified by the NELP (NIFL, 2009) and also on the instructional or pedagogical approaches. The students with significant intellectual disabilities in these studies were not relegated to rote learning of isolated skills related to these important areas of intervention but were provided with intensive opportunities to engage meaningfully with print across multiple contexts and with a variety of more literate others. These findings are important because they highlight areas of the general curriculum in reading and literacy that, when accessed, albeit often at different chronological ages, lead to positive outcomes for students with significant intellectual disabilities.

\section{Using Assistive Technology to Support Emergent Literacy Learning}

In the above studies, several simple technologies played an important role in the success of the interventions. For example, single-message voice output devices were used by the teachers in the MEville to WEville study and by the mothers in the book-sharing interactions with their daughters. In both cases, the single-message devices were programmed with messages that supported open-ended commenting and initiation (e.g., "I know about that," "Tell me more," "What do you think?") rather than specific responses. When students are emerging in their understanding of literacy, we must support them in maximizing the number their successful interactions with more literate others during literacy activities. One means to ensure this is to program these single-message devices with open-ended responses.

Other voice output devices also play an important role during emergent literacy learning. Sequenced message devices allow students with significant intellectual disabilities and complex communication needs to engage in multi-turn interactions that help them learn about the giveand-take of communication. A sequenced message device allows the student to hit the same button repeatedly to produce a series of messages in a predetermined sequence. These sequenced messages can focus on communication acts such as providing multiple-step directions, reporting on the events of a day, or telling a story from beginning to end.

In addition to communication technologies, students who have emerging understandings of print need access to tools they can use to support their early attempts at writing. Students who are physically able can use standard computers or computers with alternative keyboards and talking word processors to explore letters, sounds, and the way they are combined to make words. Students with physical disabilities who cannot access these standard tools can use their eyes to point to letters in a display or listen to a partner verbally scan through the letters of the alphabet while pointing to each letter on a printed display. The student could use a single message voice output device to indicate WRITE THAT FOR ME or two single message devices to direct the adult to GO TO THE NEXT ONE or WRITE THAT FOR ME.

Whatever the means, students with significant intellectual disabilities who are emerging in their understandings of literacy must have ample opportunities to engage in the same type of explorations of writing that typically developing children receive as they play with crayons, chalk, markers, pencils, and pens. More information about these approaches to accessing the alphabet for writing in emergent literacy is available at the Center for Literacy and Disability Studies (CLDS) website, in the section on writing with alternative pencils (http://www.med.unc.edu/ahs/clds/).

By the time typically developing children reach kindergarten, most have had more than 1,000 hours of meaningful experiences with print (Heath, 1983). A great deal of this time is spent interacting with books both independently and through shared reading with their caregivers. For many reasons, students with significant intellectual disabilities have had far more limited opportunities to engage meaningfully with print.

One reason is that many students with significant intellectual disabilities have difficulty interacting with books or sustaining their attention on books when looking at them independently. To address this issue, a team at the University of North Carolina at Chapel Hill, led by Karen Erickson and Gary Bishop, created Tar Heel Reader (http://tarheel reader.org) Originally intended to address the needs of adolescents and young adults with significant intellectual disabilities who were emergent or early conventional readers, Tar Heel Reader now has thousands of beginning-level books for emergent and beginning readers of all ages. Written by educators and others across the globe, the content of Tar Heel Reader is driven by users' needs.

The Favorites feature allows educators to set up collections of books for students to access and browse, read, and/or listen to independently. With this collection of free books, students with intellectual disabilities should have more success in approaching the thousands of hours of interactions with print that typically developing children experience before we expect the former to begin to engage in conventional reading and writing instruction. 


\section{Conventional Literacy}

For decades, the research in conventional literacy for students with significant intellectual disabilities has concentrated almost exclusively on approaches to sight word instruction (Browder \& Xin, 1998). Although this emphasis has changed slightly over the last decade, there continues to be a need for more research directed specifically to students with significant intellectual disabilities and that investigates more of the areas involved in literacy (e.g., comprehension, fluency, phonics). Until we start to provide students with significant intellectual disabilities access to the comprehensive conventional literacy instruction that their peers receive, we will not see dramatic changes in the number of these students who are conventional readers and writers.

\section{A Comprehensive Approach to Literacy Instruction}

Students without disabilities who are learning to read in the primary grades have access each day to comprehensive instruction that addresses the multiple components of successful reading. The National Reading Panel (NRP; NICHD, 2000) defined these components as phonemic awareness, phonics, vocabulary, fluency, and text comprehension. At the very least, students must have access to instruction each day that supports their ability to read words (phonemic awareness, phonics, and word identification) and read text with comprehension (fluency, vocabulary, and text comprehension) combined with instruction aimed at improving their ability to write text to communicate with others.

In this article, this combination of instructional components is called comprehensive instruction. Unfortunately, students with significant intellectual disabilities rarely have access to comprehensive instruction that addresses each of these things (Katims, 2000). When they do receive conventional literacy instruction, it tends to involve mastery of lists of sight words (Browder, Courtade-Little, Wakeman, \& Rickelman, 2006) or skills taught in isolation. Research, however, clearly demonstrates that students with significant intellectual disabilities can make progress in conventional literacy when they have access to comprehensive instruction (Erickson, Koppenhaver, Yoder, \& Nance, 1997; Hedrick, Katins, \& Carr, 1997; Hogan \& Wolf, 2002; Ryndak, Morrison, \& Sommerstein, 1999; Wershing \& Hughes, 2002).

The lack of attention to comprehensive instruction for students with significant intellectual disabilities is likely attributable to a number of factors. For example, functional word reading is widely viewed as a critical component of education for students with significant intellectual disabilities (Browder \& Spooner, 2006), whereas developing the skills to read text with comprehension is not. Also, the prevailing belief is that individuals with developmental disabilities, particularly those with intellectual disabilities, cannot learn to decode words using phonics-based strategies and, therefore, must focus on sight word reading (Kaderavek \& Rabidoux, 2004).

Further, descriptions of methods used to provide students with intellectual disabilities with access to the general curriculum in reading and literacy recommend explicitly teaching sight word skills while "exposing" students to other components of the literacy curriculum (Browder et al., 2006) or selecting only those areas of the curriculum that are most meaningful to the child (Downing, 2005). Whatever the reason, research and practice regarding other areas of comprehensive reading instruction for students with significant intellectual disabilities is sparse. We will describe issues and instruction related to word reading and comprehension, along with assistive technologies that can support children in these areas.

\section{Reading Words}

Word identification is the component of reading that involves translating printed words into pronunciations aloud or subvocally (Cunningham, 1993; Cunningham, Koppenhaver, Erickson, \& Spadorcia, 2004). As one component of successful reading, word identification can occur in two main ways: through decoding, or using letter-sound knowledge to construct a pronunciation, or through word recognition, which requires readers to use their familiarity with the spelling of a word to match the printed word with a pronunciation stored in memory (Cunningham et al., 2004). Readers often access the meaning of words while reading them, but good readers are able to identify words that have an unknown meaning or no meaning at all (pseudowords). The ability to identify words and the ability to understand their meanings are two separate processes that each must be addressed through instruction.

Beginning word readers identify words by remembering selected visual features of the word (Gough, Juel, \& Griffith, 1992). This word reading is the earliest form of word reading and can occur in the absence of letter-sound knowledge (Ehri, 2005). The Edmark Reading Program (Riverdeep, 1992) is an example of a reading instructional program available in print and software versions that is often used with students with significant intellectual disabilities. The program teaches students to attend to the visual features rather than the letter-sound associations within the word. Like other sight word instructional programs, the Edmark Reading Program teaches word reading using what Ehri (2005) calls a prealphabetic approach that does not contribute to word reading during more advanced stages of reading.

Although most readers begin reading words using the prealphabetic approaches employed in programs such as the Edmark Reading Program, programs that apply researchbased approaches developed for students without disabilities 
immediately focus on the individual letters and letter combinations in words and the sounds associated with them. In this way, beginning readers quickly transition to using their knowledge of letter-sound relationships to construct a pronunciation and then store those pronunciations in memory (Ehri, 1998). Unfortunately, students with significant intellectual disabilities are rarely provided with the opportunity to learn to apply letter-sound knowledge in reading words. A growing body of research, however, suggests that they can learn these skills when they are provided with sequential, systematic instruction (Hanser \& Erickson, 2007).

In their review of successful approaches to word reading instruction, the NRP (NICHD, 2000) found that, to read successfully, students needed to develop skills that would allow them to decode words. Two approaches they identified are: synthetic (which emphasizes letter-sound relationships) and large-unit (which emphasizes spelling patterns within words) approaches. Neither of these approaches was determined to be superior to the other (NICHD, 2000), but each has characteristics that make it more or less accessible to students with significant intellectual disabilities. Understanding these two approaches to decoding (phonics) instruction is necessary to understanding the existing research and its application to students with significant intellectual disabilities.

Synthetic approaches. Synthetic approaches to decoding or phonics are the most widely recognized approaches. A synthetic phonics approach emphasizes individual graphemes (individual letters or letter combinations) and phonemes (the sounds those letters and letter combinations make). In synthetic approaches, the grapheme-phoneme relationships are taught individually, and then students are taught to synthesize or blend the sounds to pronounce the word. Typically, lessons present reading words that share common graphemes and phonemes, followed by opportunities to read words, sentences, and simple passages that were written specifically to provide practice with the new skills. Most programs that employ a synthetic approach require students to achieve mastery with one set of letters and sounds before introducing new letters and sounds.

Two difficulties with synthetic approaches were highlighted by the NRP (NICHD, 2000) and have been raised with regard to students with intellectual disabilities in particular (Flores, Shippen, Alberto, \& Crowe, 2004). First, blending letter sounds to create a pronunciation for a word requires the deletion of extra sounds that are made when saying the name of some consonants separately. For example, when saying the sound for the letter $p$ in isolation, an additional vowel is added, and the result is pronounced /puh/. To segment a word that begins with $p$, such as pat, the letters pronounced in isolation typically sound like $/ \mathrm{puh} / / \mathrm{a} /$ /tuh/. To blend these sounds together to say the complete word, the extra vowel sounds must be deleted.

The second challenge with a synthetic approach is the demand it places on working memory. Blending three sounds is not particularly challenging, but blending five or six sounds places significant demands on memory, because students have to remember and manage the order of the sounds.

Typically, synthetic approaches begin with learning a set of letter sounds and the skills to blend those letter sounds in simple words and nonwords. A critical component of this instruction is the need for students to produce the sounds so teachers can evaluate and correct their efforts. Many students with significant intellectual disabilities have complex communication needs that make it difficult, if not impossible, for them to articulate individual letter sounds and blend them together. With these students, alternatives must be considered. Based on the difficulty that one participant's speech presented as he attempted to sound out letters and words, Flores et al. (2004) suggested that speech and language abilities be considered carefully before selecting a synthetic phonics program.

Synthetic approaches and students with significant intellectual disabilities. Two studies investigated the effectiveness of synthetic phonics approaches developed specifically to accommodate students with intellectual disabilities and complex communication needs (Fallon, Light, McNaughton, Drager, \& Hammer, 2004; Light, McNaughton, Weyer, \& Karg, 2008). Fallon et al. (2004) investigated the effects of a direct instruction approach on the single word reading skills of students with intellectual disabilities and complex communication needs. They designed a word reading intervention using 5 short vowel sounds and 9 consonants, which were combined to create a corpus of 75 consonant-vowel and consonant-vowel-consonant words. A picture was then selected to represent each of the 75 words so students could point to an array of pictures or match words to pictures to demonstrate their word reading skills. Five students (ages 9-14) were recruited for participation. All but one had moderate levels of intellectual disabilities, and all had complex communication needs. The students worked individually with a researcher who taught them to match single sounds to the initial sounds of words, to blend sounds into words, and to read simple consonant-vowel and consonant-vowel-consonant words.

During instruction emphasizing these word reading skills, student errors were corrected using a model-prompt-check procedure. The total number of 30-minute sessions required by participants ranged from 10 to 34 . All of the participants reached criterion on the trained words, but only one reached criterion on untaught words. The lack of generalization to novel words may reflect the lack of sound blending skills, but the students reached criterion because the multiple 
presentations of the words during the sessions allowed them to map the spelling of the printed word to its internal pronunciation or picture-based meaning without applying letter-sound knowledge.

In a second study, Light et al. (2008) used similar approaches to teach letter-sound correspondences, decoding, and sight word recognition to students with intellectual disabilities and complex communication needs. Word reading was just one component of the intervention, which also included instruction in phonological awareness and lettersound correspondences before moving on to word reading instruction, reading connected text, reading comprehension, and early writing. Over the course of 16 months of instruction ( 55 hours total), one 8-year-old girl learned 20 lettersound relationships and 60 words; however, the same challenges with interpretation exist. In learning to read the words through the sounding-out strategy, the girl had repeated exposure to the printed word with its pronunciation and a picture referent. Growth in word decoding cannot be confirmed without more evidence of generalization to untaught words.

Large-unit approaches. Large-unit approaches to word reading emphasize the analysis and blending of larger parts or chunks of words such as onsets (all the letters preceding the first vowel in a syllable), rimes (all of the letters from the first vowel through the end of the syllable), and spelling patterns. Usually, large-unit approaches include instruction in decoding by analogy, through which students learn to use parts of known words to decode unfamiliar words. One benefit of large-unit approaches is that those larger units can have more meaning (because they are morphemes) and can be linked to key words that serve as points of reference for the student and the teacher (Gaskins, Downer, \& the Teachers of Benchmark School, 1986; Gaskins et al., 1988). Recent research involving large-unit approaches with struggling readers suggests that beginning readers make the most progress when large-unit approaches are combined with approaches that emphasize letter-sound relationships such as synthetic approaches (Ehri, Satlow, \& Gaskins, 2009).

Large unit approaches and students with significant intellectual disabilities. Joseph and McCachran (2003) investigated the use of word sorts, a form of large-unit word reading instruction, with students with mild-to-moderate intellectual disabilities. Intervention was provided each day for 20 minutes for 8 weeks (more than 13 hours total). All words used in the word-sort lessons had CVC or CVCC spelling patterns. During each lesson, students had 3 category words and a deck of 12 words to sort according to sound and spelling patterns in the category words. After attempting the sort, the children read the words and were encouraged to self-correct.
The results suggested that the students benefited from the instruction in terms of gains in letter and word identification, but the results were inconsistent across participants. The authors suggested that word sorts may not be effective for all students with intellectual disabilities. Current research, however, would suggest that word sorts would work best in combination with approaches emphasizing letter-sound relationships such as synthetic approaches (Ehri et al., 2009).

Combining synthetic and large-unit approaches. Hanser (2008) investigated the effectiveness of a combined approach to phonics instruction for students with complex communication needs, including one student with moderate intellectual disabilities. Across 25 days of instruction, the participants engaged in 45-60 minutes of instruction employing a spelling-based approach to synthetic phonics with word sorts and other large-unit instructional strategies. The three participants all made gains in word identification and spelling words with clear evidence of generalization beyond the items that were taught. Although the duration of the intervention was insufficient to allow the participants to become conventional readers and writers, they did make measurable gains in ability to read and spell taught and untaught words.

Using assistive technology to support word reading. The intervention that Hanser (2008) used in her investigation of word reading instruction for students with intellectual disabilities and complex communication needs is one of a number of instructional programs published in the last 5 years that employ varying forms of AT to support word identification for students with significant intellectual disabilities. Programs such as Literacy through Unity (Erickson \& Hanser, 2007) and Tango to Literacy (Donnelly \& KingDeBaun, 2008) teach students with significant intellectual disabilities to identify words while teaching them to use sophisticated augmentative and alternative communication (AAC) devices. Both of these programs target the development of letter-sound strategies to read words while teaching strategies for using the vocabulary on the communication devices to support communication. One published study of the Literacy through Unity program suggested that it has the potential to improve literacy and communication skills for students with significant intellectual disabilities using Unity communication software on a Prentke-Romich AAC device (Hanser \& Erickson, 2007).

Another new research-based program is the Accessible Literacy Learning Curriculum (Light \& McNaughton, 2009), designed to address the needs of students with developmental disabilities who cannot use speech to communicate. Students are taught to blend, segment, and recognize letter-sound relationships so they can apply the skills in decoding words. The program utilizes a direct instruction 
approach to teach each of these skills to mastery in sequence with sight word reading (reading words by attending to visual cues rather than letter-sound relationships) instruction subsequent to mastery of a letter-sound-based approach to word reading.

In addition to these structured programs that were developed to teach word identification to students with significant intellectual disabilities, a number of technologies support students in learning about letters, sounds, and their relationships with words that were not designed specifically for this population or purpose. For example, Co:Writer ${ }^{\circledR} 6$ (Don Johnston, 2009) is a word prediction program originally designed to reduce the number of keystrokes required to type a word. The most recent versions provide a much broader range of support. As students type a letter, Co:Writer ${ }^{\circledR}$ produces a list of words that begin with the sound represented by the letter (e.g., if the student types $c$, the Co:Writer ${ }^{\circledR}$ program will predict words that begin with $c$ and $s$ ). Students then can read the words in the list or run the mouse over each word to hear the computer read it aloud. If the desired word is not present, the student can type more letters representing the sounds in the desired word, and $\mathrm{Co}_{\mathrm{O}} \mathrm{Writer}^{\circledR}$ will revise its list of predicted words.

Some research evidence suggests that students with learning disabilities improve their reading, spelling, and writing skills as result of using Co:Writer ${ }^{\text {(B) }}$ (MacArthur, 1998; Staples, Heying, \& McLellan, 1995). In addition, anecdotal evidence is mounting that students with significant intellectual disabilities can learn letter sounds and apply that knowledge to read words when they have had access to $\mathrm{Co}$ :Writer ${ }^{\circledR}$ while learning to read sight words by discriminating visual features of the words (see e.g., McNulty, 2009).

Word Maker (Don Johnston, 2004) is a computer-based instructional program that was designed to support beginning and struggling readers in their learning to use lettersound knowledge to read and spell words. Although the program was not designed with students with significant intellectual disabilities as the target, some students involved in projects with the Center for Literacy and Disability Studies are using it successfully in conjunction with teacherdirected instruction. Specifically, these students are completing a teacher-directed lesson from the book Systematic Sequential Phonics They Use (Cunningham, 2000), upon which the software was developed, and then they are independently completing the parallel lesson in Word Maker to practice applying the skills. This combination, though not the subject of research to date, is leading to improved reading and spelling for the students involved.

\section{Reading Text with Comprehension}

The purpose of reading is to comprehend meaning that is conveyed in print (Adams, 1990). Historically, reading comprehension has been overlooked in reading research because it was believed to be a byproduct of successful word recognition (Lipson \& Wixson, 2009). Today, it is understood that successful reading comprehension involves concurrently extracting and constructing meaning from text via a process involving interaction of the reader, the text, and the activity (RAND Reading Study Group, 2002).

The Simple View of Reading (Gough \& Tumner, 1986) offers an explanation of the manner in which these component skills interact in successful reading with comprehension. The Simple View holds that reading is a combination of decoding (linking printed words with their pronunciations) and linguistic comprehension (interpreting word level semantic information within a sentence or text). Obviously, reading a text with comprehension requires successfully reading the words; however, adequate word reading skills do not ensure successful reading with comprehension (Nation \& Norbury, 2005). Students can possibly have the skills to read all of the words in a text without having the skills to understand them (Hoover \& Gough, 1990; Nation \& Norbury, 2005).

Research confirms a relationship between poor reading comprehension and weak receptive language skills (Nation, 2005; Snowling \& Hulme, 2005). For example, in one study, students with Down syndrome and Williams syndrome who had weak receptive language skills demonstrated reading comprehension abilities commensurate with their receptive, oral language skills (Snowling \& Hulme, 2005). Given that individuals with significant intellectual disabilities typically have concomitant language impairment, it is necessary to provide systematic comprehension instruction as part of their comprehensive literacy instruction.

Text comprehension. At least two different aspects of written language or text comprehension must be addressed through instruction. The first is knowledge of text structures and the assumptions that authors make about readers. The second is knowledge of the world and the receptive understandings of vocabulary and other oral language skills. Developing knowledge of text structures requires experience with a broad range of text types including both narrative and expository texts, as well as notes, letters, online text, poems, and all of the other forms of text that are commonly used. An intervention that uses only a single type of text will prevent students from developing the knowledge of text structures required to support comprehension.

In oral language, the ability to understand how language is used is called pragmatics. In written language, pragmatics is directly related to knowledge of text structures and the things that authors expect their readers to accomplish while reading. For example, most texts require students to make inferences to fill in gaps while reading, using a combination of information in the text and knowledge they bring to the 
reading event (Kintsch \& Rawson, 2005). When they fail to make inferences or fill in gaps by drawing upon their own knowledge, poor reading results (Cain \& Oakhill, 1999). As with oral language, however, development of this ability to make inferences while reading requires broad experience and informative feedback. Just as students can develop pragmatic skills in oral language, they can learn to make inferences while reading and generally learn how written language works.

Vocabulary. As defined by Neuman and Dwyer (2009),

\begin{abstract}
vocabulary refers to the words we must know to communicate effectively: words in speaking (expressive vocabulary) and words in listening (receptive vocabulary). Children use the words they hear to make sense of the words they will eventually see in print. Vocabulary instruction, therefore, must be more than merely identifying or labeling words. Rather, it should be about helping children to build word meanings and the ideas that these words represent. By understanding words and their connections to concepts and facts, children develop skills that will help in comprehending text. (p. 385)
\end{abstract}

Vocabulary seems to relate most to reading through its connection to receptive language comprehension. Beginning readers who can speak actually translate print to speech so they can take advantage of receptive language vocabularies, which are expected to be larger than beginning reading vocabularies (Kamil, 2004). To be successful in reading and understanding words, beginning readers must associate each printed word they encounter with a word that already exists in their oral language vocabularies. As they become more skilled, vocabulary is required for successful comprehension of connected text, and the size of one's vocabulary is directly related to reading ability (Stanovich, Cunningham, \& Freeman, 1984).

To be successful in learning to read with comprehension, students need a large oral vocabulary even when their understandings of literacy are emerging (Neuman, 2006; NIFL, 2009). Students without significant disabilities can learn new word meanings in isolation, but they are more successful when they are engaged actively in learning new words (see Dole, Sloan, \& Trathen, 1995), encounter those words repeatedly across multiple contexts, and participate in instruction that employs multiple methods (NICHD, 2000).

\section{Approaches to Comprehension Instruction}

Given the absence of information regarding comprehension instruction that specifically targets students with significant intellectual disabilities, successful approaches to teaching text comprehension must draw upon research-based approaches used with students who do not have disabilities. Further, the approaches that are employed must take into account that many students with significant intellectual disabilities have complex communication needs that make it difficult, if not impossible, for them to engage ongoing discussions while reading. At the CLDS, this has led to the use of a five-step comprehension lesson framework based on the work of Tierney and Cunningham (1984), which supports students in comprehending text. Five steps are used in a before, during, after instructional framework.

\section{Step 1: Build or activate background knowledge.}

The knowledge of the world that a reader brings to a text is critical to eventually understanding that text. This knowledge of the world, or background knowledge, sometimes can be called up from an existing knowledge base, but in other cases it must be taught. Students' background knowledge can be activated by asking them to (a) recall all of the words they can think of related to a topic; (b) categorize words that relate to the topic to be read; or (c) recall a specific event, activity, or experience that relates to the topic to be read.

Background knowledge can be built by (a) teaching students the meaning of important vocabulary, (b) demonstrating completion of the type of comprehension task (e.g., sequencing) by relating it to something familiar (e.g., sequence of the meals eaten every day or the days of the week), or (c) watching a video that is related to the topic.

\section{Step 2: Set a purpose for reading.}

After activating or building the requisite background knowledge, a purpose for reading must be identified before reading. Students do eventually have to learn how to set their own purposes when reading, but during instruction, purposes should be set prior to reading. Setting a clear purpose focuses the reader's attention and increases the likelihood of success. For students with significant intellectual disabilities, a clearly stated purpose helps them attend to the important aspects of the text and combine this with their background knowledge to support their understanding of the text.

Some example purposes that are accessible to students with intellectual, physical, and/or communication impairments are the following:

- Read this so you can sequence these events (written on sentence strips).

- Read this so you can select five words that describe the main character (or setting).

- Read this so you can identify the character in the story who is most like someone you know.

Step 3: Read or listen.

Actually reading the text or listening to someone else read the text should occupy the majority of instructional 
time. If the activities in steps $1,2,4$, and 5 take longer than the reading itself, something is wrong. Time spent reading with meaning is the most important factor in supporting reading growth.

\section{Step 4: Complete a meaningful and relevant task.}

After reading, students should complete a task that relates directly to the purpose that was set before reading. If students were told to read in order to sequence, the task should require them to sequence. Nothing more! If other aspects of the text are important to understand, read it again for a different purpose.

\section{Step 5: Provide informative feedback}

The final step after reading is to work with students to understand what they did to accomplish the task. The goal is to help them understand exactly what they did to get the correct answer or to understand how they got an incorrect answer so their misunderstandings can be clarified. This step differs from correct feedback or reinforcement because it focuses on understanding how the student accomplished the task rather than on the final result of completing the task.

Certainly, other frameworks can support comprehension learning, but this before-during-after approach provides a structure to ensure that students have the support they need in building or activating their knowledge of the world. It also directs the reading process to maximize the likelihood that students with significant intellectual disabilities will be successful in learning to read with comprehension.

\section{Using Assistive Technology to Support Reading with Comprehension}

A variety of tools are available with the potential to support reading comprehension for students with significant intellectual disabilities. Some of the technologies are mainstream technologies such as YouTube and TeacherTube, which can be used to support the development of world knowledge relative to the text being read. Viewing brief videos that build relevant background knowledge prior to reading can provide a solution for students with significant intellectual disabilities who often lack life world knowledge as a result of limited experiences and language delays or disabilities.

Other technologies that can support comprehension include the numerous screen-reading tools that offer supports for vocabulary, note taking, and self-questioning or comprehension monitoring. These tools were designed originally to support readers and writers with visual impairments or learning disabilities, and they offer important supports to students with significant intellectual disabilities as well. For example, students who physically click on individual words within the text can get support in understanding the meaning of individual words. Students who are reading for a specific purpose can take notes by highlighting important information in the text. Students who struggle to remember their purpose for reading or have difficulty monitoring their own success in reading to achieve a predetermined purpose can be supported with these tools, using features that allow teachers to insert questions and prompts throughout the text.

Tar Heel Reader can be used to support students by allowing them to read easy texts on topics related to the more difficult texts they are struggling to understand. Further, teachers can use the easy texts on Tar Heel Reader to help students with significant intellectual disabilities learn how to think about text while reading text without the barriers imposed by high word-reading demands. After reading several texts on Tar Heel Reader related to more complex texts, students will have increased background knowledge and knowledge of text structures required to read other texts with comprehension.

\section{Next Steps}

The last decade has been witness to a dramatic increase in our collective knowledge of literacy, assistive technology, and significant disabilities, but we have a great deal more to learn. Currently, the vast majority of students with significant intellectual disabilities are emerging in their understandings of literacy. This may be a result of the nature of the challenges they face in learning, but the literature provides evidence that the language, cognitive, communication, physical, and sensory challenges these students face do not always prevent them from learning to read and write (Blischak, 1995; Erickson et al., 1997; Hanser \& Erickson, 2007; Light et al., 2008).

During the past 5 years, several instructional programs addressing literacy for students with significant disabilities have appeared. Most have a modest research base to support their use, but each represents only a starting place. Using these new programs in combination with what we know about emergent and conventional literacy for students without disabilities increases the likelihood that these programs will lead to success in literacy learning. Until every student with significant intellectual disabilities is given access to the tools and supports they require to emerge in their understandings of print, we will not know what is possible.

This article provides a description of our current understandings of literacy for students with significant intellectual disabilities. It draws heavily on the "mainstream reading literature" that Saunders (2007) reminded us has had "little impact on the field of mental retardation [sic], despite recognition of this gap in the literature" (p. 79). As Saunders further stated, "There is a need for intensive teaching studies 
that incorporate the best of what is known about reading instruction in typically developing children" (p. 82).

Until completion of these studies that address both the literacy content of the general curriculum and the "best of what is known about" the methods for teaching that content, we must get started with what we do know. We must carefully select' instructional methods and technologies and combine them in comprehensive approaches to literacy instruction. Whether students with significant intellectual disabilities are emerging in their literacy understandings or are among the few who are reading and writing conventionally, a comprehensive approach is most likely to address their individual areas of need while this intense need for research is being addressed.

\section{References}

AbleNet, Inc. (2004). MEville to WEville early literacy and communication program. Roseville, MN: Author.

Adams, M. A. (1990). Beginning to read: Thinking and learning about print. Cambridge, MA: MIT Press.

American Association of Intellectual and Developmental Disabilities (AAIDD). (2009). Definition of intellectual disability. Retrieved January 5, 2009, from http://www.aamr.org/index.cfm

American Psychiatric Association (APA). (2000). Diagnostic and statistical manual of mental disorders (4th ed., text. rev.). Washington, DC: Author.

Beukelman, D., \& Mirenda, P. (2005). Augmentative and alternative communication: Supporting children and adults with complex communication needs. Baltimore: Brookes.

Blischak, D. (1995). Thomas the writer: Case study of a child with severe physical, speech, and visual impairments. Language, Speech, and Hearing Services in Schools, 26, 11-20.

Blischak, D. M., \& McDaniel, M. A. (1995). Effects of picture size and placement on memory for written words. Journal of Speech and Hearing Research, 35, 1356-1362.

Boone, R., \& Higgins, K. (2007). The role of instructional design in assistive technology research and development. Reading Research Quarterly, 42(1), 135-140.

Browder, D. M., Courtade-Little, G., Wakeman, S., \& Rickelman, R. J. (2006). From sight words to emerging literacy. In D. M. Browder \& F. Spooner (Eds.), Teaching language arts, math, and science to students with significant cognitive disabilities (pp. 63-91). Baltimore: Brookes.

Browder, D. M., \& Spooner, F. (2006). Teaching language arts, math, \& science to students with significant cognitive disabilities. Baltimore: Brookes.

Browder, D. M., \& Xin, Y. P. (1998). The meta-analysis and review of sight word research and its implications for teaching functional reading to individuals with moderate and severe disabilities. Journal of Special Education, 32, 130-153.

Cain, K., \& Oakhill, J. (2007). Reading comprehension difficulties: Correlates, causes, and consequences. In K. Cain \& J. Oakhill (Eds.), Children's comprehension problems in oral and written language: A cognitive perspective (pp. 41-75). New York: Guilford Press.

Centers for Disease Control and Prevention (CDC). (2005). Intellectual disabilities. Retrieved June 16, 2008, from http://www.cdc. gov/ncbddd/dd/ddmr
Clay, M. (2005). An observation survey of early literacy achievement (2nd ed.). Portsmouth, NH: Heinemann.

Cunningham, J. W. (1993). Whole-to-part reading diagnosis. Reading and Writing Quarterly: Overcoming Learning Difficulties, 9(1), $31-49$.

Cunningham, P. (2000). Sequential systematic phonics they use. Winston-Salem, NC: Carson-Dellosa.

Cunningham, J. W., Koppenhaver, D. A., Erickson, K. A., \& Spadorcia, S. A. (2004). Word identification and text characteristics. In J. V. Hoffman \& D. Schallert (Eds.), Texts in elementary classrooms (pp. 21-38). Mahwah, NJ: Erlbaum.

Dickinson, D. K., McCabe, A., Anastasopoulos, L., Peisner-Feinberg, E. S., \& Poe, M. D. (2003). The comprehensive language approach to early literacy: The interrelationships among vocabulary, phonological sensitivity, and print knowledge among preschool-aged children. Journal of Educational Psychology, 95(3), 465-481.

Dole, J. A., Sloan, C., \& Trathen, W. (1995). Teaching vocabulary within the context of literature. Journal of Reading, 38(6), 452-460.

Don Johnston, Inc. (2004). Wordmaker [software]. Volo, IL: Author.

Don Johnston, Inc. (2009). Co: Writer ${ }^{\otimes}$ [software]. Volo, IL: Author.

Donnelly, M., \& King-Debaun, P. (2008). Tango to literacy. New York: BlinkTwice.

Downing, J. E. (2005). Teaching literacy to students with significant disabilities. Baltimore: Brookes.

Edyburn, D. L. (2003). 2002 in review: A synthesis of the special education technology literature. Journal of Special Education Technology, $18(3), 5-28$.

Edyburn, D. L. (2005). What does the research say about ... ? Journal of Special Education Technology, 20(1), 58-60.

Ehri, L. C. (1998). Grapheme-phoneme knowledge is essential for learning to read words in English. In J. L. Metsala \& L. C. Ehri (Eds.), Word recognition in beginning literacy (pp. 3-40). Mahwah, NJ: Erlbaum.

Ehri, L. C. (2005). Learning to read words: Theory, findings, and issues. Scientific Studies of Reading, 9(2), 167-188.

Ehri, L., Satlow E., \& Gaskins, I. (2009). Grapho-phonemic enrichment strengthens keyword analogy instruction for struggling young readers. Reading \& Writing Quarterly, 25(2/3), 162-191.

Erickson, K., Clendon, S., Abraham, L., Roy, V., \& Van de Carr, H. (2005). Toward positive literacy outcomes for students with significant developmental disabilities. Assistive Technology Outcomes and Benefits, 2(1), 45-54.

Erickson, K., \& Hanser, G. (2007). Literacy through unity. Wooster, IL: Prentke Romich.

Erickson, K., Koppenhaver, D., Yoder, D., \& Nance, J. (1997). Integrated communication and literacy instruction for a child with multiple disabilities. Focus on Autism and Other Developmental Disabilities, 12(3), 142-150.

Fallon, K. A., Light, J., McNaughton, D., Drager, K., \& Hammer, C. (2004). The effects of direct instruction on the single-word reading skills of children who require augmentative and alternative communication. Journal of Speech, Language \& Hearing Research, 47(6), 1424-1439.

Flores, M. M., Shippen, M. E., Alberto, P., \& Crowe, L. (2004). Teaching letter-sound correspondence to students with moderate intellectual disabilities. Journal of Direct Instruction, 4(2), 173-188.

Fossett, B., \& Mirenda, P. (2006). Sight word reading in children with developmental disabilities: A comparison of paired associate and picture-to-text matching instruction. Research in Developmental Disabilities, 27(4), 411-429.

Gaskins, 1. W., Downer, M. A., Anderson, R. C., Cunningham, P. M., Gaskins, R. W., \& Schommer, M. (1988). A metacognitive approach 
to phonics: Using what you know to decode what you don't know. Remedial and Special Education, 9, 36-41.

Gaskins, l. W., Downer, M., \& the Teachers of Benchmark School. (1986). The Benchmark word identification vocabulary development program. Media, PA: Benchmark Press.

Gough, P. B., Juel, C., and Griffith, P. L. (1992). Reading, spelling, and the orthographic cipher. In P. B. Gough, L. C. Ehri, \& R. Treiman (Eds.), Reading acquisition (pp. 35-48). Hillsdale, $\mathrm{NJ}$ : Erlbaum

Gough, P. B., \& Tumner, W. E. (1986). Decoding, reading, and reading disability. RASE: Remedial and Special Education, 7, 6-10.

Hanser, G. (2008). Investigating the effects of integrated systematic decoding, spelling, and communication instruction for students with complex communication needs. Unpublished dissertation, University of New Hampshire, Durham.

Hanser, G., \& Erickson, K. A. (2007). Integrated word identification and communication instruction for students with complex communication needs: Preliminary results. Focus on Autism and Developmental Disabilities, 22(4), 268-278.

Hatch, $\mathrm{P}$. (2009). The effects of daily reading opportunities and teacher experience on adolescents with moderate to severe intellectual disability. Unpublished doctoral dissertation, University of North Carolina at Chapel Hill.

Heath. S., B. (1983). Research currents: A lot of talk about nothing. Language Arts, 60(8), 999-1007.

Hedrick, W., Katims, D. \& Carr, N. (1999). Implementing a multimethod, multilevel literacy program for students with mental retardation. Focus on Autism and Other Developmental Disorders, 14(4), 231-239.

Hogan, N., \& Wolf, L. (2002). "+l Amam A Writer”: Literacy, strategic thinking and metacognitive awareness. In K. Erickson, D. Koppenhaver, \& D. Yoder (Eds.), Waves of words: Augmentative communicators read and write (pp. 21-40). Toronto, Canada: ISAAC.

Hoover, W. A., \& Gough, P. B. (1990). The simple view of reading. Reading and Writing: An Interdisciplinary Journal, 2, 127-160.

Individuals with Disabilities Education Improvement Act of 2004, P. L. 108-446, 20 U.S.C. $\$ 1400$ et seq.

Joseph, L. M., \& McCachran, M. (2003). Comparison of a word study phonics technique between students with moderate to mild mental retardation and struggling readers without disabilities. Education and Training in Developmental Disabilities, 38(2), 192-199.

Kaderavek, J., \& Rabidoux, P. (2004). Interactive to independent literacy: A model for designing literacy goals for children with atypical communication. Reading \& Writing Quarterly, 20, 237-260.

Kamil, M. L. (2004). Vocabulary and comprehension instruction: Summary and implications of the National Reading Panel findings. In P. McCardle \& V. Chabra (Eds.), The voice of evidence in reading research (pp. 213-234). Baltimore: Brookes.

Katims, D. (2000). Literacy instruction for people with mental retardation: Historical highlights and contemporary analysis. Education and Training in Mental Retardation and Developmental Disabilities, 35(1), 3-15.

Kintsch, W., \& Rawson, K. (2005). Comprehension. In M. Snowling,\& C. Hulme (Eds.) The science of reading: A handbook (pp. 209-226). Malden, MA: Blackwell.

Koppenhaver, D. A. (2000). Literacy in AAC: What should be written on the envelope we push? Augmentative and Alternative Communicatiom, 16, 267-277.

Koppenhaver, D. \& Erickson, K. (2003). Natural emergent literacy supports for preschoolers with autism and severe communication impairments. Topics in Language Disorders, 23(4), 283-293.
Light, J., \& McNaughton, D. (2009). Accessible literacy learning curriculum. Pittsburgh: DynaVox Mayer-Johnson.

Light, J., McNaughton, D., Weyer, M., \& Karg. L. (2008). Evidencebased literacy instruction for individuals who require augmentative and alternative communication: A case study of a student with multiple disabilities. Seminars in Speech \& Language, 29(2), 120-132.

Lipson, M. Y., \& Wixson, K. K. (2009). Assessment and instruction of reading and writing difficulties: An interactive approach. Boston: Pearson.

Luckasson, R., Borthwick-Duffy, S., \& Buntix, W. H. (2002). Mental retardation: Definition, classification, and systems of supports (10th ed.). Washington, DC: American Association on Mental Retardation.

MacArthur, C. A. (1998). Word processing with speech synthesis and word prediction: Effects on the dialogue journal writing of students with learning disabilities. Learning Disability Quarterly, $21(2), 151-166$.

Matvy, M. (2000). A silicon bullet for dyslexia: A new solution for an old problem. Exceptional Parent, 30(11), 52-56.

Mayer-Johnson, LLC. (2006). Boardmaker (Version 6) [Computer software]. Pittsburgh: Author.

McNulty, D. (2009). Teaching words as symbols for students with autism. Retrieved December 15, 2009, from http://www.donjohn ston.com/products/cowriter/research.html

Nation, K. (2005). Children's reading comprehension difficulties. In M. Snowling \& C. Hulme (Eds.) The science of reading: $A$ handbook (pp. 248-265). Malden, MA: Blackwell.

Nation, K., \& Norbury, F. (2005). Why reading comprehension fails: Insights from developmental disorders. Topics in Language Disorders, 25, 21-32.

Nation, K., \& Snowling, M. J. (2004). Beyond phonological skills: Broader language skills contribute to the development of reading. Journal of Research in Reading, 27(4), 342-356.

National Institute for Child Health and Development (NICHD). (2000). Report of the National Reading Panel: Teaching children to read (Report of the Subgroups). Bethesda, MD: National Institutes of Health.

National Institute for Literacy (NIFL). (2009). Developing early literacy: Report of the National Early Literacy Panel. Washington, DC: Author.

Neuman, S. B. (2006). The knowledge gap: Implications for early education. In D. Dickinson \& S. B. Neuman (Eds.), Handbooks of early literacy research (Vol. 2, pp. 29-40). New York: Guilford.

Neuman, S. B., \& Dwyer, J. (2009). Missing in action: Vocabulary instruction in PreK. Reading Teacher, 62(5), 384-392.

Pufpaff, L. A., Blischak, D. M., \& Lloyd, L. L. (2000). Effects of modified orthography on the identification of printed words. American Journal on Mental Retardation, 105(1), 14-24.

RAND Reading Study Group. (2002). Reading for understanding: Toward an $R \& D$ program in reading comprehension. Retrieved May 27, 2008 from http://www.rand.org/pubs/monograph_re ports/MR1465/index.html

Riverdeep. (1992). Edmark reading program, Level l. Redmond, WA: Author.

Rose, D., \& Meyer, A. (2002). Teaching every student in the digital age: Universal design for learning. Alexandria, VA: Association for Supervision and Curriculum Development.

Rose, T. L., \& Furr, P. M. (1984). Negative effects of illustrations as word cues. Journal of Learning Disabilities, 17(6), 334-337.

Ryndak, D., Morrison, A., \& Sommerstein, L. (1999). Literacy before and after inclusion in general education settings: A case study. $J A S H, 24,5-22$. 
Samuels, J. (1967). Attentional processes in reading - The effects of pictures on the acquisition of reading responses. Minneapolis: University of Minnesota. (ERIC Clearinghouse ED014370).

Saunders, K. J. (2007). Word-attack skills in individuals with mental retardation. Mental Retardation \& Developmental Disabilities Research Reviews, 13(1), 78-84.

Saunder, R. J., \& Solman, R. T. (1984). The effect of pictures on the acquisition of a small vocabulary of similar sight-words. British Journal of Educational Psychology, 54(3), 265-275.

Sénéchal, M., LeFevre, J., Smith-Chant, B. L., \& Colton, K. V. (2001). On refining theoretical models of emergent literacy: The role of empirical evidence. Journal of School Psychology, 39(5), $439-460$.

Singer, H., Samuels, S. J., \& Spiroff, J. (1973-1974). The effects of pictures and contextual conditions on learning responses to printed words. Reading Research Quarterly, 9(4), 555-567.

Singh, N. N., \& Solmon, J. (1990). A stimulus control analysis of the picture-word problem in children who are mentally retarded: The blocking effect. Journal of Applied Behavior Analysis, 23, $525-532$.

Skoto, B. G., Koppenhaver, D. A., \& Erickson, K. A. (2004). Parent reading behaviors and communication outcomes in girls with Rett syndrome. Exceptional Children, 70(2), 145-166.

Slater Software Incorporated. (2008). PixWriter [Computer software]. Guffey, CO: Author.

Snowling, M., \& Hulme, C. (2005). Learning to read with a language impairment. In M. Snowling \& C. Hulme (Eds.) The science of reading: A handbook (pp. 397-412). Malden, MA: Blackwell.

Stanovich, K. E., Cunningham, A. E., \& Freeman, D. J. (1984). Intelligence, cognitive skills and early reading progress. Reading Research Quarterly, 19, 278-303.
Staples, A., Heying, K., \& McLellan, J. (1995) A study of the effects of Co:Writer word prediction software on the writing achievement of students with learning disabilities. Retrieved December 15, 2009 , from http://www.donjohnston.com/products/cowriter/research.html

State of Queensland Department of Education. (2006). What is intellectual impairment? Retrieved June 16, 2008, from http:/education.qld.gov.au/studentservices/learning/disability/generalinfo/int ellectual/ii2.html

Storch, S. A., \& Whitehurst, G. J. (2002). Oral language and coderelated precursors to reading: Evidence from a longitudinal structural model. Developmental Psychology, 38(6), 934-947.

Teale, W., \& Sulzby, E. (1986). Emergent literacy: Writing and reading. Norwood, NJ: Ablex.

Tierney, R. J., \& Cunningham, J. W. (1984). In P. D. Pearson, R. Barr, M. L. Kamil, \& P. Mosenthal (Eds.), Handbook of reading research (pp. 609-655). New York: Longman.

U.S. Department of Education (2002). Twenty-fourth annual report to Congress on the implementation of the Individuals with Disabilities Education Act. Washington, DC: Author.

U.S. Department of Health and Human Services. (2008), About ADD: What is a developmental disability? Retrieved June 16,2008, from http://www.acf.hhs.gov/programs/add/addaboutwhatis.html

Wershing, A., \& Hughes, C. (2002). Just give me words. In K. Erickson, D. Koppenhaver, \& D. Yoder (Eds.), Waves of words: Augmentative communicators read and write (pp. 45-56). Toronto, Canada: ISAAC.

Widgit Software. (2002). Writing with symbols 2000 (Version 2.6) [Computer software]. Warwickshire, UK: Widget Software. 